\title{
COMPARISON BETWEEN BLOOD AND CRYSTALLOID CARDIOPLEGIA IN PATIENTS WITH LEFT VENTRICULAR DYSFUNCTION UNDERGOING CORONARY SURGERY
}

\author{
Radim Brát ${ }^{1}$, Jan Tošovský ${ }^{1}$, Jaroslav Januška ${ }^{1}$, Leo Derych ${ }^{1}$, Svatopluk Velkoborský1, Vilém Bruk ${ }^{1}$, Jan Dominik ${ }^{2}$
}

University Hospital Ostrava: Department of Cardiac Surgery'; University Teaching Hospital in Hradec Králové: Department of Cardiac Surgery ${ }^{2}$

Summary: This study was done to compare the protective effect of blood and crystalloid cardioplegia in patients with left ventricular dysfunction undergoing coronary artery bypass grafting (CABG). Sixty consecutive patients with left ventricular ejection fraction $<35 \%$ scheduled for CABG with the use of cardiopulmonary bypass without additional procedures were randomly divided into two groups. In the first group we used cold blood cardioplegia, in the second group cold crystalloid cardioplegia, both delivered only ortogradly. We measured hemodynamic data in early hours after operation, enzyme release and we collected other clinical data which could be influenced by perioperative myocardial protection. There was no death in either group. We also didn't find any significant difference in incidence of perioperative myocardial infarction, arrhytmias and use of intraaortic balloon pumping between both groups. In an early hours after operation in the group with blood cardioplegia we found significantly better hemodynamic data (LVSWI, RVSWI) and significantly lower enzyme release. We conclude, that cold blood cardioplegia shows superior perioperative myocardial protection resulting in earlier restoration of myocardial function. This difference could be important in patients with high degree of left ventricular dysfunction.

Key words: Blood cardioplegia; Myocardial protection; Coronary artery bypass grafting

\section{Introduction}

Myocardial protection during cardiosurgical procedures is one of the leading problems in cardiac surgery. A lot of studies concerning this topic were published, but the optimal method wasn't found $(1,2,3)$. It wasn't also unambiguously solved, which of the two main types of cardioplegia, that means blood or crystalloid cardioplegia, shows better myocardial protection. There were published a lot of studies showing better myocardial protection with the use of blood cardioplegia $(4-12)$, on the other hand some authors didn't confirm this difference $(13,14)$. It is also difficult to compare the results of different studies because of the fact, that they are used different protocols of cardioplegia.

This study was done to compare the protective effect of blood and crystalloid cardioplegia in patients with left ventricular dysfunction with a view to the changes during early postoperative phase.

\section{Material and Methods}

From January 1998 to July 1999, sixty consecutive patients with left ventricular ejection fraction $<35 \%$ scheduled for coronary artery bypass grafting without additional procedures were randomly divided into two groups. Crystalloid cardioplegia was used in the first group and blood cardioplegia in the second one.

Blood cardioplegia was administered with the cardioplegia delivery set at a ratio of $4: 1$. After institution of cardiopulmonary bypass and aortic cross clamp $1000 \mathrm{ml}$ of high-potassium $(25 \mathrm{mEq} / \mathrm{l})$ cold blood cardioplegia was delivered into the aortic root. After completing of the first peripheral anastomose low-potassium (16 mEq/1) cold blood cardioplegia was continuously infused through the grafts. Another $500 \mathrm{ml}$ of cold low-potassium blood cardioplegia was delivered into the aortic root every 20 minutes. Neither „hot shot“ nor substrate enriched cardioplegia was used. We have been using this protocol since 1995 in our institution.

In the crystalloid cardioplegia group the protocol was as followed. After institution of cardiopulmonary bypass and aortic cross clamp $1000 \mathrm{ml}$ of cold crystalloid cardioplegia (St. Thomas Infusia) was delivered into the aortic root. After completing of the first peripheral anastomose cold crystalloid cardioplegia was continuously infused through the grafts. The composition of the cardioplegic solutions was published in previous study (12).

All patients in this study were operated under general anaesthesia by the use of cardiopulmonary bypass. In both 
groups moderate systemic hypothermia $\left(32^{\circ} \mathrm{C}\right)$ and topical hypotermia were used. Internal mammary artery bypasses were implanted as last anastomoses. The surgical technique and staff involved were basicaly the same during the period of this study.

The hemodynamic variables were measured by the thermal dilution technique with a Swan-Ganz catheter before institution of cardiopulmonary bypass and than at 1, 2, 4 and 6 hours after terminating of cardiopulmonary bypass. The last measurement was performed the first postoperative day in the morning. All the measurements were acquired when the patient's conditions were hemodynamicaly stable.

Blood samples for determination of the serum levels of total creatine kinase $(\mathrm{CK})$, and catalytic activity of its $\mathrm{MB}$ isoenzyme (CK - MB) were taken 1, 5, 7 and 11 hours after terminating of cardiopulmenary bypass and then the first and second postoperative day in the morning.

Recorded operative and postoperative clinical variables included mortality rate, perioperative myocardial infarction rate, use of intraaortic balloon counterpulsation, arrhytmias in postoperative period, defibrillation and cardioversion after unclamping the ascending aorta etc.

Comparison between groups were made with Student's t-test when appropriate, were used to test frequencies. Values of $\mathbf{P}<0,05$ were considered statistically significant.

\section{Results}

There were no significant difference between the groups in the clinical profile (see Tab. 1). The ejection fraction in crystalloid and blood cardioplegia group was $28,3 \%$ and $27,3 \%$ respectively. The clinical results are summarised in Tab. 2 . There was no death in both groups and we didn't have to use intraaortic balloon counterpulsation or left ventricular assist device in either group. The perioperative myocardial infarction rate was higher in a crystalloid group, but the difference wasn't statistically significant. Also the plasmatic level of potassium before leaving cardiopulmonary bypass as well as total blood loss after operation and length of hospitalisation after operation didn't show statistically significant differences between groups. There was less incidence of the attacks of the atrial fibrillations in postoperative course in the crystalloid cardioplegia group, but this difference wasn't statisticaly significant. There was a rather high percentage of patients requiring defibrillation before leaving cardiopulmonary bypass in both groups, but in the crystalloid cardioplegia group it was significantly higher.

Important differences between groups were found in enzymatic response in postoperative period. Some of the data are shown in Tab. 3 and Fig. 1. Average CK and CK - MB was in the blood cardioplegia group lower during the whole examined period, but statistically significant this difference was only in the early hours after operation.

Important part of this study was hemodynamic data measurement. The changes in LVSWI and RVSWI comparing to preoperative values are shown in Tab. 4 and Fig. 2. We can see significant differences between groups. There was the decrease in LVSWI and RVSWI immediately after operation and the preoperative value was reached in about 3 5 hours after operation in crystalloid cardioplegia group. On the other hand we didn't find this decrease in blood cardioplegia group. This difference between groups was statistically significant only 1 hour after the operation. Other hemodynamic data didn't show any statistically significant difference. We also didn't find any significant difference between groups in the need of postoperative inotropic support.

Tab 1: Clinical characteristics of patients in crystalloid and blood cardioplegia group.

\begin{tabular}{|l|c|c|c|}
\hline & Crystalloid & Blood & p Value \\
\hline No. of patients & 30 & 30 & NS \\
\hline Age (years) & $63 \pm 9$ & $67 \pm 9$ & NS \\
\hline Sex (Men / Women) & $22 / 8$ & $24 / 8$ & NS \\
\hline BSA (m2) & $1,87 \pm 0,19$ & $1,84 \pm 0,15$ & NS \\
\hline LVEF (\%) & $28,3 \pm 3,4$ & $27,3 \pm 5,1$ & NS \\
\hline No. of grafts & $3,7 \pm 0,8$ & $3,4 \pm 0,7$ & NS \\
\hline CPB time (min) & $71 \pm 18$ & $68 \pm 18$ & NS \\
\hline $\begin{array}{l}\text { Aortic cross-clamp } \\
\text { time (min) }\end{array}$ & $37 \pm 13$ & $35 \pm 11$ & NS \\
\hline
\end{tabular}

Where applicable, data are shown as the mean \pm the standard deviation.

BSA = body surface area

$\mathrm{LVEF}=$ left ventricular ejection fraction

$\mathrm{CPB}=$ cardiopulmonary bypass

$\mathrm{NS}=$ not significant $(\mathrm{p}>0,05)$

Tab 2: Clinical results.

\begin{tabular}{|l|c|c|c|}
\hline & Crystalloid & Blood & $\mathrm{p}$ Value \\
\hline No. of patients & 30 & 30 & $\mathrm{NS}$ \\
\hline Death (within 30 days) & 0 & 0 & $\mathrm{NS}$ \\
\hline LVAD & 0 & 0 & $\mathrm{NS}$ \\
\hline IABP & 0 & 0 & $\mathrm{NS}$ \\
\hline Perioperative infarction & $2(6,7 \%)$ & $1(3,3 \%)$ & $\mathrm{NS}$ \\
\hline Spontaneus return of SR & $3(10 \%)$ & $11(37 \%)$ & $\mathrm{p}<0,05$ \\
\hline $\begin{array}{l}\text { Serum K }{ }^{+} \text {before } \\
\text { leaving CPB (mmol/1) }\end{array}$ & $4,6 \pm 0,6$ & $4,8 \pm 0,7$ & $\mathrm{NS}$ \\
\hline Blood loss (ml) & $747 \pm 221$ & $737 \pm 181$ & $\mathrm{NS}$ \\
\hline $\begin{array}{l}\text { AF in postoperative } \\
\text { period }\end{array}$ & $8(27 \%)$ & $11(37 \%)$ & $\mathrm{NS}$ \\
\hline Postoperative stay (days) & $8 \pm 2$ & $9 \pm 2$ & $\mathrm{NS}$ \\
\hline
\end{tabular}

Where applicable, data are shown as the mean \pm the standard deviation.

LVAD = left ventricular assist device

$\mathrm{IABP}=$ intraaortic baloon pump

$\mathrm{SR}=$ sinus rhythm $\mathrm{CPB}=$ cardiopulmonary bypass

$\mathrm{AF}=$ atrial fibrilation $\mathrm{NS}=$ not significant $(\mathrm{p}>0,05)$ 
Tab. 3: Enzymatic response in postoperative period.

\begin{tabular}{|c|c|c|c|c|c|c|c|c|c|}
\hline & \multicolumn{6}{|c|}{$\mathrm{CK}$} & \multicolumn{3}{|c|}{ CK - MB } \\
\hline & $2 *$ & $6 *$ & $8^{*}$ & $12 *$ & $24 *$ & $48 *$ & $2 *$ & $6 *$ & $8 *$ \\
\hline Crystalloid & 6,9 & 10,6 & 10,91 & 11,39 & 11,28 & 8,36 & 0,84 & 1,06 & 0,79 \\
\hline Blood & 5,2 & 7,5 & 8,06 & 9,44 & 10,05 & 7,95 & 0,63 & 0,48 & 0,47 \\
\hline p - Value & $\mathrm{p}<0,05$ & $\mathrm{p}<0,05$ & NS & $\mathrm{NS}$ & $\mathrm{NS}$ & $\mathrm{NS}$ & $\mathrm{p}<0,05$ & $\mathrm{p}<0,05$ & $\mathrm{p}<0,05$ \\
\hline
\end{tabular}

values are means in $\mu \mathrm{kat} / 1$

*hours after terminating of cardiopulmonary bypass

$$
\begin{aligned}
& \mathrm{CK}=\text { creatine kinase } \\
& \mathrm{CK}-\mathrm{MB}=\text { isoenzyme of } \mathrm{CK} \\
& \mathrm{NS}=\text { not significant }(\mathrm{p}>0,05)
\end{aligned}
$$

Tab. 4: LVSWI and RVSWI in postoperative period (changes against preoperative status).

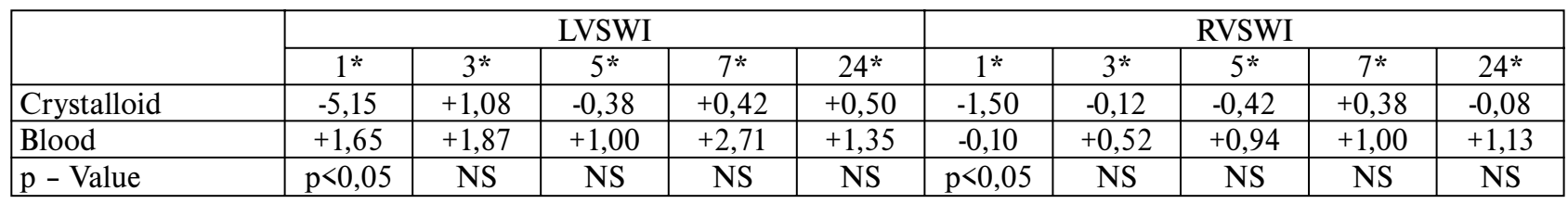

values are mean differences between postoperative and preoperative status (g. $\mathrm{m} / \mathrm{m}^{2}$ )

*hours after terminating of cardiopulmonary bypass

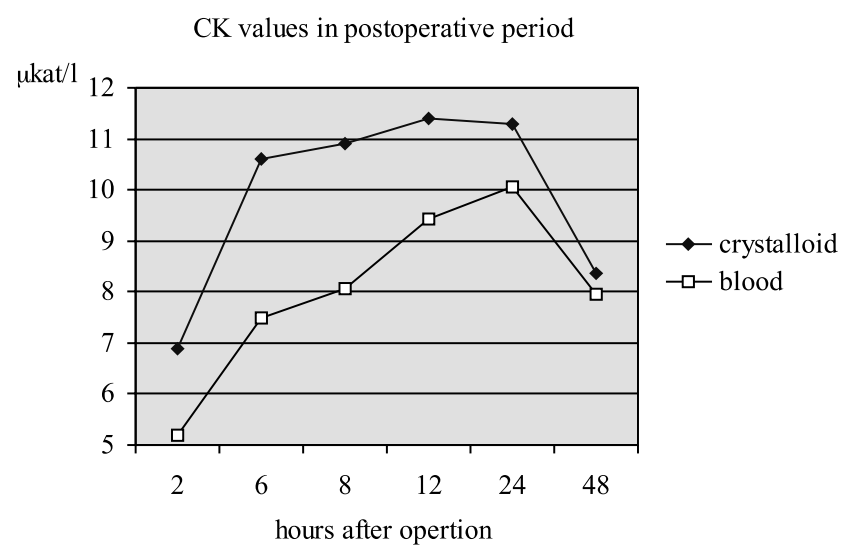

Fig. 1: CK values in postoperative period.

\section{Discussion}

This study was the first part of the study supported by the grant of IGA MH CR No. NA 5583 - 3. We suppose that presented groups are big enough to publish the results, but they are not big enough to draw common conclusions on the basis of them. Most of the investigators dealing with this topic conclude, that the difference between blood and crystalloid cardioplegia could be found only in patients with high degree of left ventricular dysfunction or in patients with metabolically compromised myocardium. To form rather compact group of such patients we included only patients with left ventricular ejection fraction $<35 \%$ scheduled for elective coronary artery bypass grafting without additional procedures.
LVSWI = left ventricular stroke work index RVSWI = right ventricular stroke work index $\mathrm{NS}=$ not significant $(\mathrm{p}>0,05)$

LVSWI and RVSWI in postoperative period (changes against preoperative status)

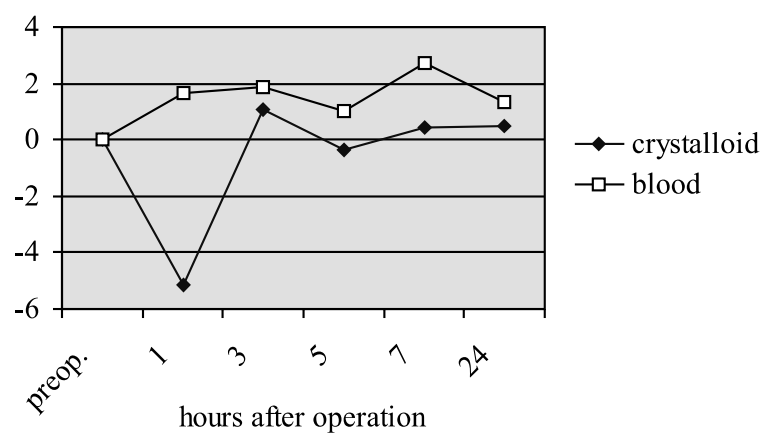

Fig.2: LVSWI and RVSWI in postoperative period (changes against preoperative status)

The difference in enzymatic response after operation was find also by others $(5,9,15)$. The hemodynamic data measurement wasn't performed in early hours after operations in most of the published studies and as we have showed, there is no difference between groups later after operation. The exceptions are for example studies published by Iverson (9), Jin (6) and some other, who also found better hemodynamic data in early hours after operation in blood cardioplegia group.

\section{Conclusions}

We can summarise that we didn't find significant differences in mortality, perioperative myocardial infarction rate and need of mechanical heart support in postoperative pe- 
riod between blood and crystalloid cardioplegia groups. The cardiospecific enzyme response was significantly lower in the blood cardioplegia group and the LVSWI and RVSWI was significantly higher in the blood cardioplegia group one hour after operation.

We conclude, that blood cardioplegia shows earlier improvement of myocardial function after the operation. Blood cardioplegia could be beneficial in patients with severe left ventricular dysfunction, because in these patients the left ventricular dysfunction in early hours after operation can reach the critical point leading to collapse of the circulation.

This study was supported by the grant of IGA MH CR No. NA 5583 - 3.

\section{References}

1. Hricák V. Peroperačná ochrana myokardu. In: Hricák V. Perioperačná kardiologická starostlivost v kardiochirurgii dospelého veku..SAP-Slovak Academic Press 1996:52-80.

2. Cordell R. Milestones in the Development of Cardioplegia. Ann Thorac Surg 1995;60:793-6

3. Bojar RM. Myocardial Protection. In: Bojar RM. Adult cardiac surgery. Boston: Blackwell Scientific Publications, 1992:37-77.

4. Ikonomidis $\mathrm{J}$, Rao $\mathrm{V}$, Weisel $\mathrm{R}$ et al. Myocardial protection for coronary bypass grafting: The Toronto hospital perspective. Ann Thorac Surg 1995;60:824-32.

5. Fremes SE, Christakis GT, Weisel RD et al. A clinical trial of blood and crystalloid cardioplegia. J Thorac Cardiovasc Surg 1984;88:726-41.

6. Jin XY, Gibson DG, Pepper JR. Early changes in regional and global left ventricular function after aortic valve replacement. Comparison of crystalloid, cold blood, and warm blood cardioplegias. Circulation 1995;92(suppl II):II-155-II-162.
7. Biagioli B, Giomarelli P, Gnudi G et al. Myocardial function in early hours after coronary artery bypass grafting: comparison of two cardioplegic methods. Ann Thorac Surg 1993:56(6):1315-23.

8. Khuri SF, Warner KG, Josa M et al. The superiority of continuos cold blood cardioplegia in the metabolic protection of the hypertrophied human heart. J Thorac Cardiovasc Surg 1988;95:442.

9. Iverson LIG, Young JN, Ennix CL Jr et al. Myocardial protection: A comparison of cold blood and cold crystalloid cardioplegia. J Thorac Cardiovasc Surg 1984;87:509-16.

10. Feindel CM, Tait GA, Wilson GJ, Klement P, MacGregor DC. Multidose blood versus crystalloid cardioplegia: Comparison by quantitative assessment of irreversible myocardial injury. J Thorac Cardiovasc Surg 1984;87(4):585-95.

11. Prasad K, Bharadwaj B, Card RT. Effects of blood and crystalloid cardioplegia on cardiac function at organ and cellular levels during hypothermic cardiac arrest. Ang 1988;1:23-33.

12. Brat R, Tosovsky J, Januska J. Blood cardioplegia in patients with left ventricular dysfunction. Cardiol 1998;7(1):15-7.

13. Yau TM, Ikonomidis JS, Weisel RD et al. Which techniques of cardioplegia prevent ischemia? Ann Thorac Surg 1993;56:1020-8.

14. Roberts AJ, Woodhall DD, Knauf DG, Alexander JA. Coronary artery bypass graft surgery: Clinical comparison of cold blood potassium cardioplegia, warm cardioplegic induction, and secondary cardioplegia. Ann Thorac Surg 1985;40:483

15. Singh AK, Farrugia R, Teplity C, Karlson KE. Electrolyte versus blood cardioplegia: Randomised clinical and myocardial ultrastructural study. Ann Thorac Surg 1982;33:217.

Submitted April 2000.

Accepted June 2000.

MUDr. Radim Brát, University Hospital Ostrava, Department of Cardiac Surgery, 17. listopadu 1790, 70852 Ostrava - Poruba, Czech Republic. e-mail: radim.brat@fnspo.cz 